\title{
Article \\ Application of Pelvic Circumferential Compression Devices in Pelvic Ring Fractures-Are Guidelines Followed in Daily Practice?
}

\author{
Valerie Kuner ${ }^{1, *}{ }^{\oplus}$, Nicole van Veelen ${ }^{1}\left(\mathbb{D}\right.$, Stephanie Studer ${ }^{2}$, Bryan Van de Wall ${ }^{1}$, Jürgen Fornaro ${ }^{3}$, \\ Michael Stickel ${ }^{4}$, Matthias Knobe ${ }^{1}{ }^{\mathbb{D}}$, Reto Babst ${ }^{5}{ }^{(}$, Frank J.P. Beeres ${ }^{1}$ and Björn-Christian Link ${ }^{1}$ (I) \\ 1 Department of Orthopaedic and Trauma Surgery, Cantonal Hospital Lucerne, 6000 Luzern, Switzerland; \\ Nicole.vanVeelen@luks.ch (N.v.V.); Bryan.VandeWall@luks.ch (B.V.d.W.); Matthias.Knobe@luks.ch (M.K.); \\ Frank.Beeres@luks.ch (F.J.P.B.); Bjoern-Christian.Link@luks.ch (B.-C.L.) \\ 2 Medical Faculty, University of Zurich, 8091 Zurich, Switzerland; StephanieStuder@gmx.ch \\ 3 Department of Radiology, Cantonal Hospital Lucerne, 6000 Luzern, Switzerland; Juergen.Fornaro@luks.ch \\ 4 Department of Emergency Care, Cantonal Hospital Lucerne, 6000 Luzern, Switzerland; \\ Michael.Stickel@icloud.com \\ 5 Department of Health Science and Medicine, University of Lucerne, 6002 Luzern, Switzerland; \\ Reto.Babst@luks.ch \\ * Correspondence: Valerie.Kuner@googlemail.com
}

\section{check for} updates

Citation: Kuner, V.; van Veelen, N.; Studer, S.; Van de Wall, B.; Fornaro, J.; Stickel, M.; Knobe, M.; Babst, R.; Beeres, F.J.P.; Link, B.-C. Application of Pelvic Circumferential Compression Devices in Pelvic Ring Fractures-Are Guidelines Followed in Daily Practice?. J. Clin. Med. 2021, 10, 1297. https://doi.org/ $10.3390 / \mathrm{jcm} 10061297$

Academic Editor: Roman Pfeifer

Received: 14 February 2021

Accepted: 18 March 2021

Published: 21 March 2021

Publisher's Note: MDPI stays neutral with regard to jurisdictional claims in published maps and institutional affiliations.

Copyright: (c) 2021 by the authors. Licensee MDPI, Basel, Switzerland. This article is an open access article distributed under the terms and conditions of the Creative Commons Attribution (CC BY) license (https:/ / creativecommons.org/licenses/by/ $4.0 /)$.
Abstract: Early administration of a pelvic circumferential compression device (PCCD) is recommended for suspected pelvic trauma. This study was conducted to evaluate the prevalence of PCCD in patients with pelvic fractures assigned to the resuscitation room (RR) of a Level I trauma center. Furthermore, correct application of the PCCD as well as associated injuries with potential clinical sequelae were assessed. All patients with pelvic fractures assigned to the RR of a level one trauma center between 2016 and 2017 were evaluated retrospectively. Presence and position of the PCCD on the initial trauma scan were assessed and rated. Associated injuries with potential adverse effects on clinical outcome were analysed. Seventy-seven patients were included, of which 26 (34\%) had a PCCD in place. Eighteen (23\%) patients had an unstable fracture pattern of whom ten (56\%) had received a PCCD. The PCCD was correctly placed in four $(15 \%)$ cases, acceptable in $12(46 \%)$ and incorrectly in ten (39\%). Of all patients with pelvic fractures $(n=77,100 \%)$ treated in the RR, only one third ( $n=26,34 \%$ ) had a PCCD. In addition, 39\% of PCCDs were positioned incorrectly. Of the patients with unstable pelvic fractures $(n=18,100 \%)$, more than half either did not receive any PCCD ( $n=8,44 \%$ ) or had one which was inadequately positioned $(n=2,11 \%)$. These results underline that preclinical and clinical education programs on PCCD indication and application should be critically reassessed.

Keywords: pelvic ring fracture; PCCD; position; associated injuries

\section{Introduction}

About $20 \%$ of polytrauma patients have a pelvic injury [1], with an estimated incidence of about 23 per 100,000 persons per year [2,3]. The examination of pelvic stability is part of the primary survey of trauma patients as an unstable pelvic ring fracture may result in severe intra- or retroperitoneal bleeding [4-6]. If, based on the mechanism of injury or clinical findings, an unstable pelvic ring injury is suspected, current guidelines recommend applying a pelvic circumferential compression device (PCCD) $[4,7,8]$ to minimize the risk of intrapelvic haemorrhage and promote coagulation by realigning the pelvic ring and therefore reducing the pelvic volume [6,9-12]. A further option to reduce anterior diastasis is simple internal rotation of the lower extremities, which can be held by tape as reported by Gardner et al. However, this technique is problematic if the lower limbs are unstable due to long bone fractures [13-15]. Ideally, the PCCD is applied in the preclinical setting 
directly at the site of the accident. Typically, it is left in place until either the injury is ruled out or treatment is initiated $[16,17]$. The PCCD should be positioned over the greater trochanters to allow for optimal transmission of forces via the proximal femur to the pelvis to reduce anterior diastasis $[18,19]$. Potential disadvantages of PCCDs such as skin necrosis and nerve lesions have been described in case reports [20-26].

This study aimed to evaluate the prevalence and quality of PCCD application in pelvic fractures of patients assigned to the resuscitation room (RR) in a level I trauma center in Switzerland as well as to assess potential adverse effects in relation to associated injuries using a PCCD.

The hypothesis of this study is that the majority of patients with pelvic fractures treated in the resuscitation room at this level I trauma center have a correctly positioned PCCD in place and few adverse effects occur.

\section{Materials and Methods}

This article was written in accordance with the STROBE statement [27]. The study was approved by the Ethics Committee of Northwest- and Central Switzerland (project ID 2018-00411). The need for informed consent was waived.

\subsection{Study Design, Setting and Participants}

The imaging and electronic patient records of all consecutive patients treated in the $R R$ of a level one trauma center in Switzerland were evaluated retrospectively for the years 2016 and 2017. Resuscitation room management at this trauma center follows a defined algorithm, which is based on the Advanced Trauma Life Support (ATLS) algorithm [7,28,29] and has been adjusted according to the Whitebook Medical Care of the Severely Injured of the German Society for Trauma Surgery [30]. If hemodynamically stable, all patients receive a whole-body computer tomography (CT) after the primary survey has been completed. All patients with a traumatic pelvic fracture diagnosed in the whole-body CT were included in this study. Fragility and subacute fractures were excluded. Fractures obtained from lowenergy trauma such as a fall from standing height were defined as fragility fractures [31]. In fragility fractures the ligament structures remain intact, so there is no major bleeding and therefore no role for PCCDs. Subacute fractures were defined as fractures with visible callus formation with or without previous documentation of the fracture.

\subsection{Data Measurement and Variables}

Demographic data of each patient were collected from the electronic medical records (Medfolio, Nexus AG, Donaueschingen, Germany) as well as the Swiss Trauma Register (STR) and the register of the German Society for Trauma Surgery (DGU). In these registers there are six possible trauma mechanisms to allocate the case to: car, motorcycle, cyclist, pedestrian, fall from height or other (such as explosion or blow). Any fall that was from higher than standing height was defined as a fall from height. The New Injury Severity Score (NISS) total was compiled and divided into groups $<16$ and $\geq 16$ points on the NISS scale [32-34]. To be able to classify the fractures and evaluate the positioning of the PCCD patients had to have had a CT. Hemodynamically unstable patients, who required immediate intervention prior to CT imaging were therefore excluded.

Images were viewed using the Picture Archiving and Communication System (PhönixPACS GmbH, Freiburg i.Br, Germany). All fractures were classified according to the modified Tile AO classification by an orthopaedic resident and revised by a fellowshiptrained pelvic surgeon $[35,36]$. Unstable fractures were defined as Tile B1, B3, C1, C2 or C3. Stable fractures were defined as Tile A1, A2, A3 and B2. Type B2 fractures (ipsilateral internal rotation injury) were classified as stable fractures, as these fractures are caused by an internal rotation force and the volume of the pelvis is not enlarged by the injury. Further, it is assumed that the anatomy of these fractures is restored by the elastic recoil of the pelvis [35]. For these reasons, such injuries do not benefit from the use of a PCCD. Fractures that could not be classified according to Tile, such as acetabular fractures classified 
according to Judet and Letournel [37] and sacral fractures according to Denis [38] I-III plus sacral transversal, sacral U- and H-shaped fractures, were rated as stable fracture patterns, since these do not benefit from the use of a PCCD. Further, it was assessed whether the fracture involved the neuroforamina.

In the catchment area of this trauma center two different types of PCCD, the T-PODTM (Cybertech Medical, Laverne, CA, USA) and the SAM Pelvic-sling IITM (SAM Medical Products, Tualatin, OR, USA) are in use [39,40].

Presence upon arrival in the emergency room (yes or no), type (the T-POD lap loop or the SAM Pelvic-sling II) and position of a PCCD were assessed on the CT scans. The position of the PCCD was rated as 'correct' if it covered both greater trochanters completely, 'acceptable' if the PCCD partly covered the greater trochanters and 'incorrect' if the PCCD did not cover the greater trochanters at all (Figure 1) $[18,19]$.

All associated injuries based on the CT findings like presence of bladder injury, neuroforaminal fracture involvement, vascular injury, pelvic hematoma and based on medical records of presence of neurogenic bladder disorder, posttraumatic peripheral neurologic injury of the lower extremities and skin necrosis were recorded.

Bladder injury, neurogenic bladder disorder, neuroforaminal fracture involvement with simultaneous posttraumatic peripheral neurologic injury of the lower extremities and vascular injury were defined as associated injuries which could be aggravated by the application of a PCCD.

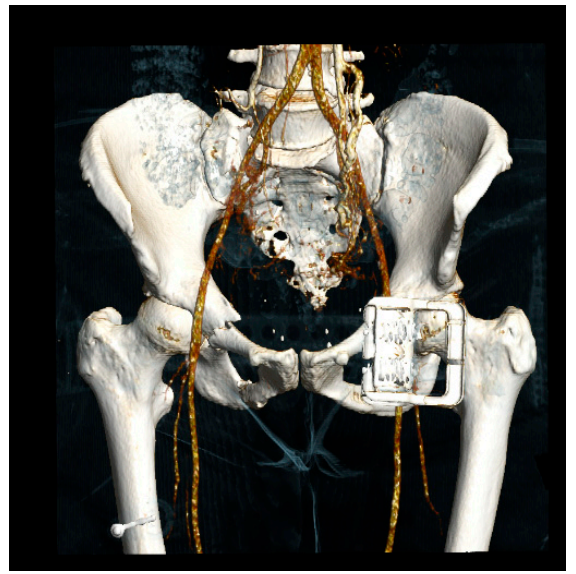

(A)

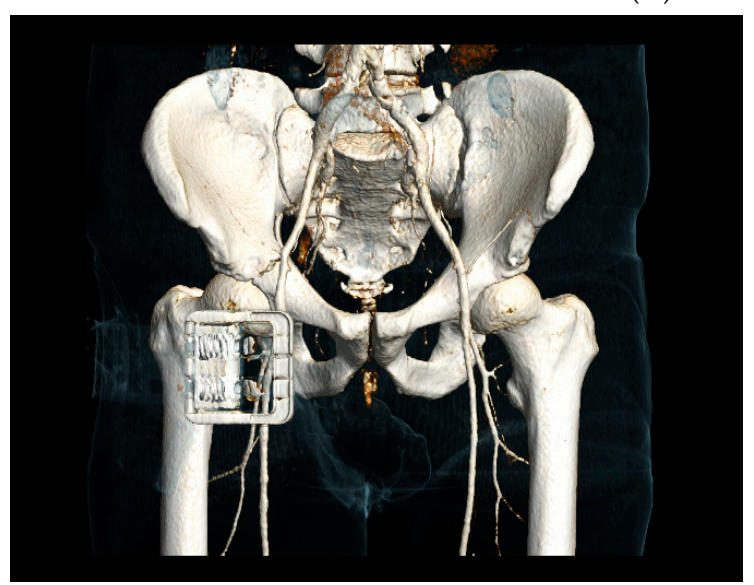

(B)
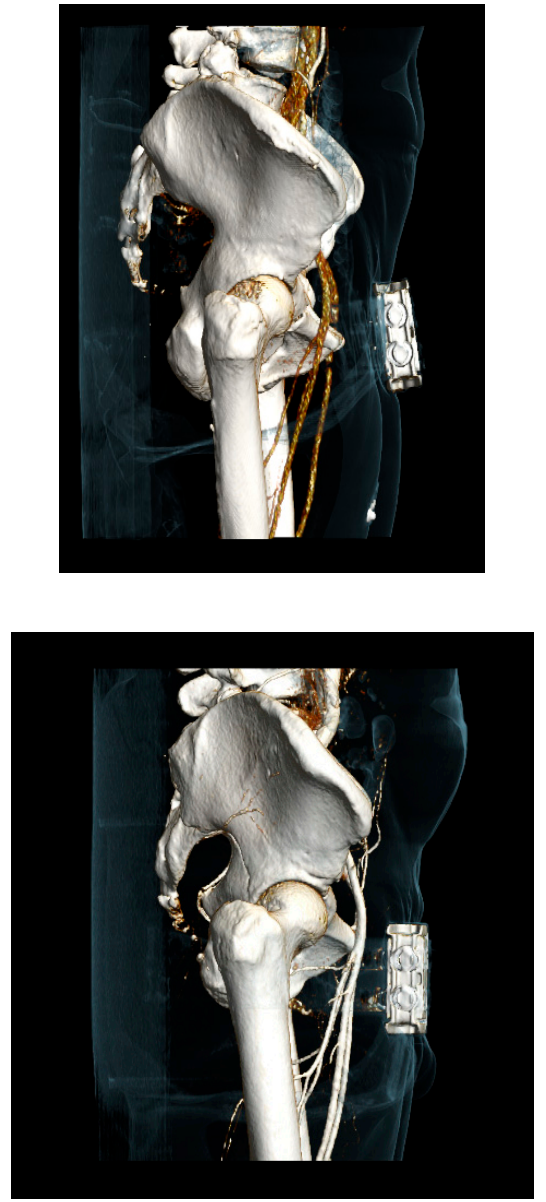

Figure 1. Cont. 

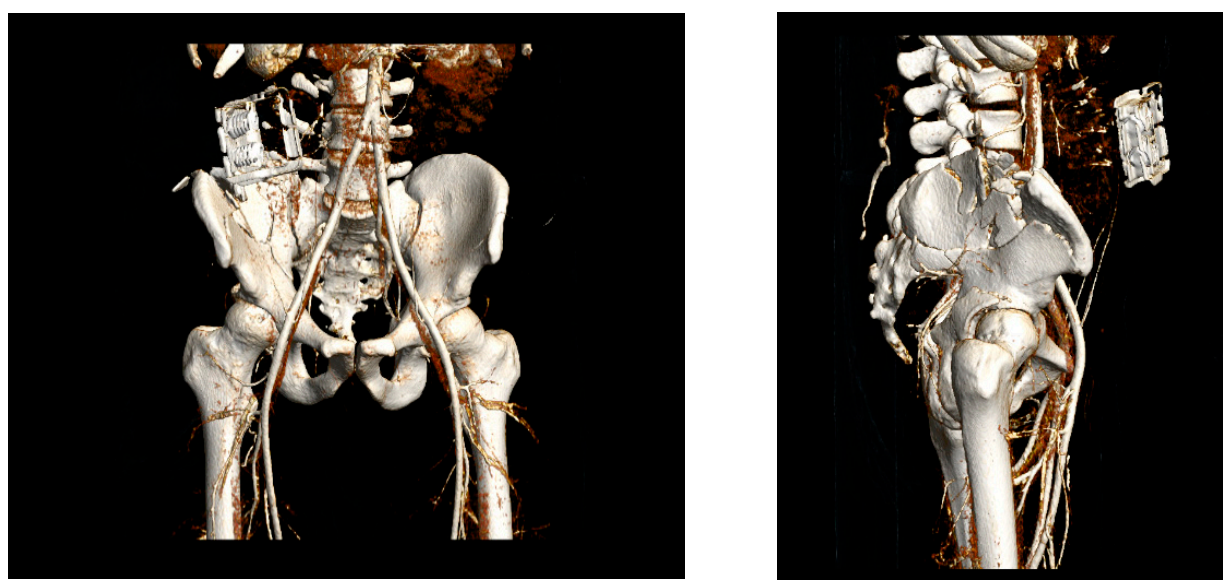

(C)

Figure 1. Pelvic circumferential compression device (PCCD) positioning (example of the SAM Pelvicsling II). (A) Correct positioning of a PCCD at the level of the trochanters; (B) Acceptable positioning of a PCCD with partial coverage of the trochanters; (C) Incorrect positioning of a PCCD without any covering of the trochanters.

\subsection{Statistical Methods}

The data collected were analysed using SPSS (IBM ${ }^{\circledR}$ SPSS $^{\circledR}$ Statistics 24, IBM, Armonk, NY, USA). Mean values, medians, standard deviation and percentages were calculated. The Fisher exact test was used for the statistical analysis of associated injuries and PCCD presence (significance level $p<0.05$ ). Subgroup analysis was tempted stratified for fracture stability by using the Fisher exact test. The Chi- Square Test was used to analyze the relationship between the positioning of PCCD and the associated injuries (significance level $p<0.05)$.

\section{Results}

A total of 730 patients were admitted to the RR during the study period. Eighty-two $(11 \%)$ had a pelvic fracture. All patients were hemodynamically stable enough to receive a CT prior to any intervention. Four patients with a fragility fracture and one patient with a subacute pubic fracture were excluded leaving a total of 77 patients (Figure 2). The demographic data are summarized in Table 1. All patients sustained their injuries by blunt trauma.

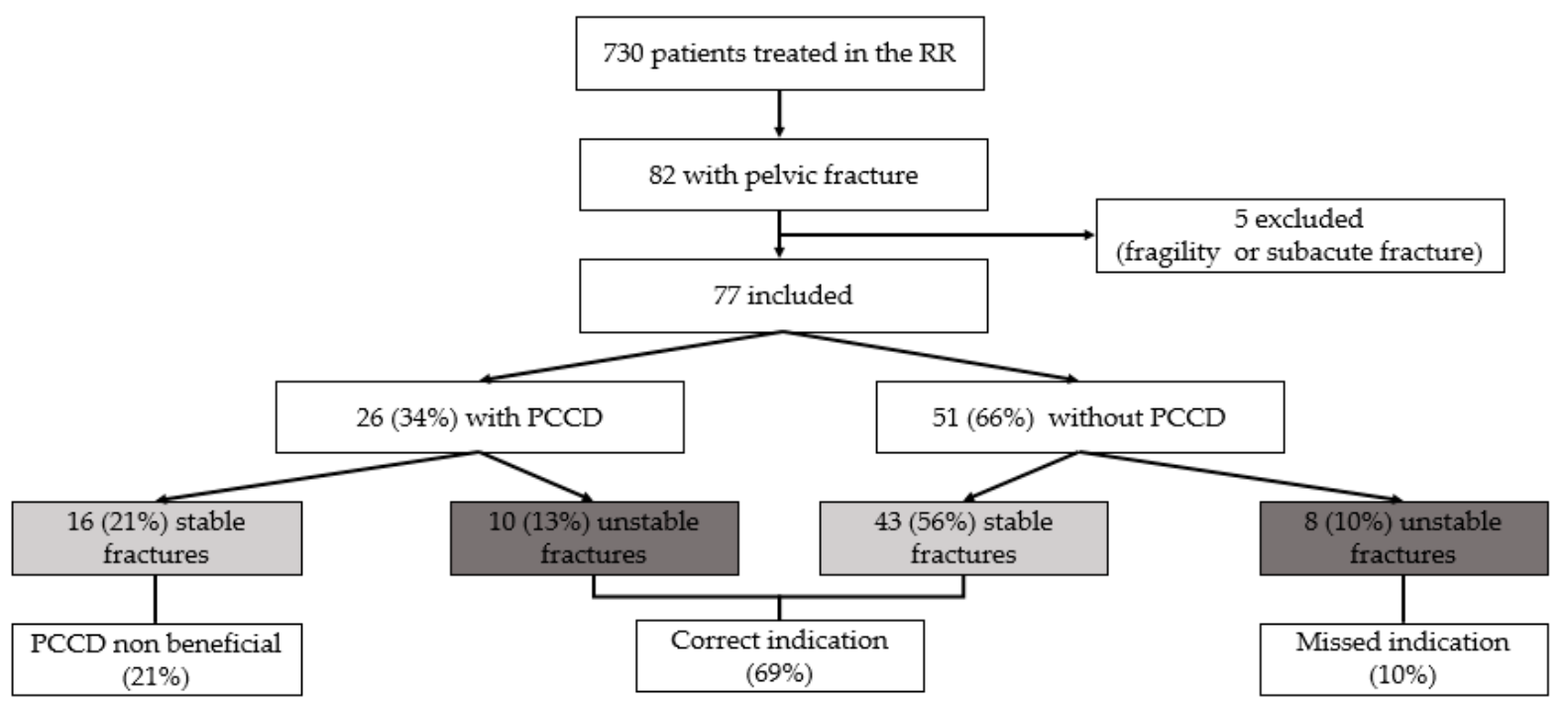

Figure 2. Included patients, prevalence of a PCCD and indication for PCCD. 
Table 1. Demographic data.

\begin{tabular}{|c|c|c|}
\hline Demographic Data & $\mathbf{N}$ & Mean \\
\hline \multicolumn{3}{|l|}{ Sex } \\
\hline Male & $49(64 \%)$ & \\
\hline Female & $28(36 \%)$ & \\
\hline Age & & 50 years (range $14-93, \mathrm{SD} \pm 21.2$ ) \\
\hline \multicolumn{3}{|l|}{ Trauma mechanism } \\
\hline Blunt & $77(100 \%)$ & \\
\hline \multicolumn{3}{|l|}{ Type of accident } \\
\hline Car & $6(8 \%)$ & \\
\hline Motorcycle & $13(17 \%)$ & \\
\hline Cyclist & $6(8 \%)$ & \\
\hline Pedestrian & $8(10 \%)$ & \\
\hline Fall from height & $36(47 \%)$ & \\
\hline Other (like blow, explosion) & $8(10 \%)$ & \\
\hline NISS & & 20 (range $4-66, S D \pm 16)$ \\
\hline \multicolumn{3}{|l|}{ NISS $\geq /<16$} \\
\hline$\geq 16$ & $54(70 \%)$ & \\
\hline$<16$ & $23(30 \%)$ & \\
\hline \multicolumn{3}{|l|}{ Intensive medical treatment } \\
\hline Yes & $40(52 \%)$ & \\
\hline No & $37(48 \%)$ & \\
\hline Survivors & $71(92 \%)$ & \\
\hline Death & $6(8 \%)$ & \\
\hline Length of hospital stay (days) & & 11 (0-98 days, $\mathrm{SD} \pm 14)$ \\
\hline
\end{tabular}

Twenty-six (34\%) patients had a PCCD in place at the time of the CT examination (Figure 2). Out of these, 24 PCCDs had been placed preclinically, for the remaining two no reliable documentation on the time of application was found. Eighteen $(69 \%)$ patients had the T-POD device and eight (31\%) the SAM pelvic sling II in place.

Fracture classification according to Tile is listed in Table 2. There were no $\mathrm{C} 1$ fractures in the cohort. Fifty-eight (75\%) patients could be classified according to Tile. The remaining $25 \%$ had acetabular or sacral fractures which could not be classified according to Tile and were therefore assigned to the stable fracture patterns (Table 2).

Table 2. Prevalence of fractures and pelvic circumferential compression device (PCCD).

\begin{tabular}{|c|c|c|c|}
\hline Fracture Type & $\begin{array}{c}\text { Total } \\
n=77\end{array}$ & $\begin{array}{c}\text { PCCD Placed } \\
n=26\end{array}$ & $\begin{array}{c}\text { PCCD Not Placed } \\
\quad n=51\end{array}$ \\
\hline \multicolumn{4}{|l|}{ Pelvic ring fractures according to } \\
\hline Tile & $58(75 \%)$ & & \\
\hline \multicolumn{4}{|l|}{ stable and unstable } \\
\hline $\mathrm{A} 1$ & $2(3 \%)$ & 0 & 2 \\
\hline A2 & $16(21 \%)$ & 4 & 12 \\
\hline A3 & $2(3 \%)$ & 1 & 1 \\
\hline B1 & $5(6 \%)$ & $2^{1}$ & $3^{2}$ \\
\hline B2 & $20(26 \%)$ & 5 & 15 \\
\hline B3 & $8(10 \%)$ & $5^{1}$ & $3^{2}$ \\
\hline $\mathrm{C} 1$ & $0(0 \%)$ & 0 & 0 \\
\hline $\mathrm{C} 2$ & $2(3 \%)$ & $2^{1}$ & 0 \\
\hline $\mathrm{C} 3$ & $3(4 \%)$ & 1 & $2^{2}$ \\
\hline acetabular fracture & $17(22 \%)$ & 6 & 11 \\
\hline isolated sacral fracture & $2(3 \%)$ & 0 & 2 \\
\hline additional femoral neck fracture & 3 (in 1 bilateral) & 1 & 2 \\
\hline additional Pipkin fracture & 2 & 2 & 0 \\
\hline
\end{tabular}

${ }^{1}$ Ten $(13 \%)$ correct indications for PCCD. ${ }^{2}$ Eight (10\%) unstable fractures, indication for PCCD. 
Eighteen $(23 \%)$ patients had an unstable fracture pattern, of which ten $(56 \%)$ received a PCCD, while 16 (27\%) of the patients with a stable fracture had one applied. This leaves a total of 51 patients without PCCD, 43 (73\%) of the patients with stable fractures, and eight (44\%) of those with unstable fractures.

In total ten (13\%) patients correctly received a PCCD based on the fracture pattern, eight $(10 \%)$ should have received a PCCD, $43(56 \%)$ did not get a PCCD since there was no indication for application and 16 (21\%) received a PCCD although indication was not given (Figure 2).

The position of the PCCD was correct in four (15\%) cases, acceptable in $12(46 \%)$ and incorrect in ten (39\%) (Table 3). Regarding the ten patients with unstable fractures, PCCD position was correct in one patient, acceptable in seven patients and inadequate in two (Table 3).

Table 3. PCCD positioning.

\begin{tabular}{ccc}
\hline Position of PCCD & Unstable Factures $\boldsymbol{n = 1 0}$ & Stable Fractures $\boldsymbol{n}=\mathbf{1 6}$ \\
\hline correct & $1(10 \%)$ & $3(19 \%)$ \\
acceptable & $7(70 \%)$ & $5(31 \%)$ \\
incorrect & $2(20 \%)$ & $8(50 \%)$ \\
\hline
\end{tabular}

The type of PCCD and the respective positioning are listed in (Table 4).

Table 4. PCCD type (T-POD or SAM Pelvic Sling) in unstable fractures.

\begin{tabular}{cccc}
\hline \multicolumn{2}{c}{ Position of T-POD $(\boldsymbol{n}=\mathbf{7})$} & \multicolumn{2}{c}{ Position of SAM Pelvic Sling $(\boldsymbol{n}=\mathbf{3})$} \\
\hline correct & $1(14 \%)$ & correct & 0 \\
acceptable & $5(71 \%)$ & acceptable & $2(67 \%)$ \\
incorrect & $1(14 \%)$ & incorrect & $1(33 \%)$ \\
\hline
\end{tabular}

The associated injuries are listed in Table 5. One patient had two associated injuries (neurogenic bladder disorder and neuroforaminal fracture involvement with simultaneous posttraumatic peripheral neurologic injury of the lower extremities). In this collective no PCCD related adverse effects such as skin necrosis were registered.

Patients with applied PCCD showed a significantly higher rate of associated injuries like bladder injury $(n=3)$, neurogenic bladder disorder $(n=3)$, neuroforaminal fracture involvement with simultaneous posttraumatic peripheral neurologic injury of the lower extremities $(n=1)$, traumatic vascular injury $(n=7)$ than patients without PCCD according to the Fisher exact test ( $p=0.0075)$ (Table 6).

Within the group of PCCD patients, the subgroup analysis stratified for fracture stability showed no significant difference regarding the incidence of associated injuries for unstable fracture patterns (Fisher exact test $p=0.3137$ ) (Table 6), while there was a significant association in the stable fracture group (Fisher exact test $p=0.0278$ ) (Table 6).

There was a statistically significant relationship between the positioning of PCCD and the occurrence of associated injuries according to the Chi- Square Test $(X 2(1, N=77)=5.0667$, $p<0.05$ ) (Table 7). 
Table 5. Associated injuries of pelvic fracture.

\begin{tabular}{|c|c|c|}
\hline Associated Injury & $n=77$ & Fracture Type \\
\hline \multirow{3}{*}{ Bladder injury } & \multirow{3}{*}{$3(4 \%)$} & B1 \\
\hline & & B2 + Denis I + acetabular anterior wall \\
\hline & & acetabular anterior column, posterior hemitransverse \\
\hline \multirow{3}{*}{$\begin{array}{l}\text { Neurogenic bladder } \\
\text { disorder }\end{array}$} & \multirow{3}{*}{$3(4 \%)$} & B2 + sacrum fracture $\mathrm{H}$ - type \\
\hline & & $\begin{array}{l}\mathrm{C} 3+\text { sacrum fracture } \mathrm{H} \text { - type }+ \text { acetabular } \\
\text { anterior column } 1\end{array}$ \\
\hline & & acetabular anterior column \\
\hline \multirow{14}{*}{$\begin{array}{l}\text { Neuroforaminal fracture } \\
\text { involvement }\end{array}$} & \multirow{14}{*}{$14(18 \%)$} & $\mathrm{A} 3+$ transverse sacrum fracture \\
\hline & & B2 + Denis II \\
\hline & & B2 + Denis II \\
\hline & & B2 + Denis II \\
\hline & & B2 + Denis II \\
\hline & & B2 + Denis II \\
\hline & & B2 + Denis III \\
\hline & & $\mathrm{B} 2$ + sacrum fracture H- type \\
\hline & & $\mathrm{B} 3+$ transverse sacrum fracture \\
\hline & & B3 + sacrum fracture U- type \\
\hline & & C2 + Denis II \\
\hline & & $\mathrm{C} 3$ + sacrum fracture $\mathrm{H}$ - type \\
\hline & & $\begin{array}{l}\text { Denis II + acetabular anterior colum } \\
\text { with hemitransverse }\end{array}$ \\
\hline & & Denis II + acetabular 2 colum fracture \\
\hline \multirow{4}{*}{$\begin{array}{l}\text { Nerve lesion of the lower } \\
\text { extremities }\end{array}$} & \multirow{4}{*}{$4(5 \%)$} & $\mathrm{C} 3+$ sacrum fracture $\mathrm{H}$ - type \\
\hline & & sacrum fracture H- type \\
\hline & & acetabular transverse fracture \\
\hline & & acetabular 2 colum fracture \\
\hline $\begin{array}{l}\text { Neuroforaminal fracture } \\
\text { involvement }+ \\
\text { posttraumatic peripheral } \\
\text { neurologic injury of the } \\
\text { lower extremities }\end{array}$ & $1(1 \%)$ & $\begin{array}{l}\mathrm{C} 3+\text { sacrum fracture } \mathrm{H} \text { - type }+ \text { acetabular } \\
\text { anterior column }{ }^{1}\end{array}$ \\
\hline \multirow{7}{*}{ Traumatic vascular injury } & \multirow{7}{*}{$7(9 \%)$} & $\mathrm{A} 3$ + transverse sacrum fracture \\
\hline & & B1 \\
\hline & & B1 \\
\hline & & B2 + Denis II \\
\hline & & B2 + Denis III \\
\hline & & C2 + Denis II \\
\hline & & acetabular transverse fracture \\
\hline
\end{tabular}


Table 5. Cont.

\begin{tabular}{|c|c|c|}
\hline Associated Injury & $n=77$ & Fracture Type \\
\hline \multirow{19}{*}{ Pelvic hematoma } & \multirow{19}{*}{$19(25 \%)$} & A2 \\
\hline & & A2 \\
\hline & & A2 + Denis I \\
\hline & & A3 + transverse sacrum fracture \\
\hline & & B1 + Denis I \\
\hline & & B2 + Denis I \\
\hline & & B2 + Denis I \\
\hline & & B2 + Denis I \\
\hline & & B2 + Denis II \\
\hline & & $\mathrm{B} 2$ + sacrum fracture $\mathrm{H}$ - type \\
\hline & & B2 + acetabular anterior wall \\
\hline & & B3 \\
\hline & & B3 + Denis I \\
\hline & & B3 + Denis I \\
\hline & & C2 + Denis I \\
\hline & & $\begin{array}{l}\mathrm{C} 3+\text { sacrum fracture } \mathrm{H} \text { - type }+ \text { acetabular } \\
\text { anterior colum }\end{array}$ \\
\hline & & acetabular anterior colum with hemitransverse \\
\hline & & acetabular 2 colum fracture \\
\hline & & $\begin{array}{c}\text { left acetabular transverse + posterior wall, right } \\
\text { acetabular posterior wall }\end{array}$ \\
\hline
\end{tabular}

Table 6. Contingency table of all documented associated injuries in relation to applied PCCD. (a) Contingency table of all documented associated injuries in patients with unstable fractures in relation to applied PCCD. (b) Contingency table of all documented associated injuries in patients with stable fractures in relation to applied PCCD.

\begin{tabular}{cccc}
\hline & PCCD & No PCCD & \\
\hline Associated injury & $9(69 \%)$ & $4(31 \%)$ & 13 \\
No associated injury & $17(27 \%)$ & $47(73 \%)$ & 64 \\
& 26 & 51 & 77 \\
\hline
\end{tabular}

(a)

\begin{tabular}{cccc}
\hline & PCCD & No PCCD & \\
\hline Associated injury & $4(80 \%)$ & $1(20 \%)$ & 5 \\
No associated injury & $6(46 \%)$ & $7(54 \%)$ & 13 \\
& 10 & 8 & 18 \\
\hline
\end{tabular}

(b)

\begin{tabular}{cccc}
\hline & PCCD & No PCCD & \\
\hline Associated injury & $5(62.5 \%)$ & $3(37.5 \%)$ & 8 \\
No associated injury & $11(22 \%)$ & $40(78 \%)$ & 51 \\
& 16 & 43 & 59
\end{tabular}

The Fisher exact test statistic value is 0.0075 . The result is significant at $p<0.05$. (a) The Fisher exact test statistic value is 0.3137 . The result is not significant at $p<0.05$. (b) The Fisher exact test statistic value is 0.0278 . The result is significant at $p<0.05$. 
Table 7. Contingency table of all documented associated injuries in relation to the position of the applied PCCD.

\begin{tabular}{cccc}
\hline & $\begin{array}{c}\text { PCCD Correct or } \\
\text { PCCD Acceptable }\end{array}$ & $\begin{array}{c}\text { PCCD Incorrect or } \\
\text { No PCCD }\end{array}$ & \\
\hline Associated injury & $6(43 \%)$ & $8(57 \%)$ & 14 \\
\hline No associated injury & $10(16 \%)$ & $53(84 \%)$ & 63 \\
\hline & 16 & 61 & 77 \\
\hline
\end{tabular}

The chi-square statistic is 5.0667. The $p$-value is 0.02439 . Significant at $p<0.05$.

\section{Discussion}

In this retrospective study comprising of 77 patients with a pelvic fracture only one third $(26 / 77 ; 34 \%)$ had a PCCD applied. The position of the PCCD was correct in four $(15 \%)$ cases, acceptable in $12(46 \%)$ and incorrect in ten (39\%).

Several recent studies are in accordance with these findings that only a minority of patients with pelvic ring fractures are preclinically treated with a PCCD [41-44]. The largest cohort so far is described by another Swiss study overlooking a period of 6 years that found a PCCD applied in only 552/2366 (23\%) of the cases [45]. Also in a recent study of Vaidya et al. one third of patients with unstable pelvic fractures did not receive a PCCD [41]. In this study, the rate was even higher with $44 \%(8 / 18)$.

According to studies that mainly examined external rotation injuries and the reduction of symphyseal diastasis by PCCD, the PCCD needs to be positioned over the greater trochanters for optimal efficiency $[18,19,46]$. Retrospective studies which analysed the position of the PCCD in relation to the trochanters have shown that the position is incorrect in up to $50 \%[18,47-50]$.

In this cohort, 39\% had incorrect positioning. Williamson et al. found a similar suboptimal placing of PCCD in $43.5 \%, 39.7 \%$ were placed superior and $3.8 \%$ inferior to the greater trochanter line [48]. Other studies demonstrate a PCCD misalignment of up to 50\% [49,50].

Of the 10 patients with an unstable fracture and a PCCD seven (70\%) received the T-POD and three (30\%) the SAM pelvic sling II. No superiority of one PCCD model over the other could be found by Knops et al. [51]. This study cohort was too small to evaluate the superiority of one type of device over the other.

The retrospective observational design and the relatively small size of the study population limit the conclusive strength of this study. The small number of patients who received a PCCD does not allow for statistical evaluation regarding the type of PCCD applied and limited the statistical power of subanalysis regarding a connection between PCCD positioning and potential adverse effects on associated injuries. The correction for other confounders was not possible due to the low sample size, therefore, it was chosen to only stratify for stable and unstable fractures. A low rate of accurate indication and correct PCCD application has been reported by several authors [18,41-45,47-50].

The evaluation of pelvic ring stability at the site of an accident is often hampered by several factors such as patient consciousness, environmental circumstances and clothing. These inherent factors seem to limit the accuracy of the clinical evaluation of pelvic stability. Studies assessing these difficulties concluded that since clinical stability testing of the pelvis showed low sensitivity [46-48], the accident mechanism was a more relevant factor influencing the decision on whether or not a PCCD is indicated [52-54]. However, the trauma mechanism might be unclear in a substantial proportion of cases emphasising the challenges encountered in the field. The classification into stable fractures, for which the PCCD is not beneficial, and unstable fractures, for which the indication is given, was used for retrospective analysis. This classification was based on the review of CT images of the fractures, which is naturally impossible for preclinical staff who must rely on clinical signs and the mechanism of injury to judge the stability of a pelvic injury. It does however, highlight the fact that unstable pelvic fractures were undersupplied with PCCDs in this study population and that there is room for improvement. 
The low rate of correctly positioned PCCD could be addressed by sensitising and instructing paramedics and RR personnel on accurate identification of anatomical landmarks. Williamson et al. defined the correct position of the PCCD as a position between the tip of the greater trochanter and the inferior border of the lesser trochanter. He found a significantly higher risk for misplacement of the PCCD if the distance between those anatomic landmarks was small $(<8.9 \mathrm{~cm})$ and in females [48]. Due to smaller body size in females the palpable bony mass of the greater trochanter is also smaller. This might cause additional problems in positioning the PCCD correctly. Familiarization with different PCCD models through training seems to be an additional factor [44,55], as different types of PCCDs will require knowledge for their correct positioning in relation to palpable landmarks. Obesity or secondary dislocation during patient transport of the PCCD are also factors that can hamper correct positioning.

The accident kinematics as well as the preclinical assessment and initial clinical examination should trigger the suspicion of a pelvic ring injury [4,7]. If an unstable pelvic ring injury is suspected, stabilization using a PCCD is an effective temporary measure in an emergency situation $[4,7,26]$. Additional advantages of a PCCD are pain control, haemorrhage control $[39,56]$, reduced transfusion requirement [12,57], reduction in the length of hospitalization [12,57] and decreased mortality [12]. PCCDs are non-invasive and can be applied rapidly on the scene of an accident [40].

In the preclinical phase, the PCCD is the gold standard for pelvic stabilization. The stabilization of pelvic fractures with severe and persistent hemodynamic instability can be achieved by invasive procedures in the RR such as the C-clamp [58-60] for pelvic ring lesions of type $C$ and by external fixation [61-64] for the B-type [65,66]. PCCDs show an equivalence to invasive procedures like the $\mathrm{C}$-clamp, which requires more user knowledge, time, training and equipment [67]. It also provides comparable stability to invasive procedures such as the external fixators [68]. However, in contrast to the PCCD, the c-clamp and external fixator can be used for definitive treatment.

In respect to the fracture pattern, to our knowledge there is no evidence in the literature that compression of internal rotation injuries or acetabular fractures with a PCCD may cause adverse effects [10,11,42,51]. However, known potential disadvantages of PCCD application are pressure decubitus or aggravating nerve compression with long lasting application, as described in case reports and studies that analyze pressure measurement on models or healthy subjects [22,69-72]. No skin necrosis complication occurred in this patient population. Due to short transport distances and prompt patient care in the catchment area of central Switzerland the paramedic should not hesitate to apply a PCCD because of potential risk of skin necrosis. However, the current study found more potential aggravation of associated injuries with PCCD application (Table 6). Despite these differences being statistically significant, the total number of patients included in this study population was relatively low, prohibiting the ability to draw a sound conclusion. It however demonstates the need for further investigation into this topic.

Interestingly, this potential aggravation of associated injuries was statistically significant for stable fractures (Table 6), but not for unstable fractures (Table 6) in the subgroup analysis. The definition of a stable (A1-3, B2) and unstable (B1, B3, C1-3) fracture chosen for this study may be a potential confounder in this sub-analysis. It was assumed that the anatomy in B2 fractures is restored by the elastic recoil of the pelvis near to normal so it does not benefit from the use of a PCCD. The compressive effect of a PCCD, however, may reproduce or even aggravate the initial accident mechanism, therefore potentially leading to further injuries. Out of the five patients with stable fractures who received a PCCD and had associated injuries two were B2 fractures. Both of these cases had a vascular injury. The other three were two A2 and one A3 fracture. Further studies are needed to address risk factors in terms of PCCD effects. These could give rise to balance potential life- saving benefits against potential adverse events [26].

Conversely, the rate of PCCD in patients with pelvic fractures in general and specifically in patients with unstable pelvic ring fractures is rather low. Naturally, there seems to 
be room for improvement in education. In Central Switzerland, paramedics receive lessons on how to correctly apply a PCCD as part of their training, this includes an instructional video and a handout. Qualified paramedics must complete a total of $40 \mathrm{~h}$ of mandatory annual training which includes the application of PCCDs. In the latest (10th) edition of the ATLS Student Manual, for the first time a video on PCCD application including anatomic landmark instructions is linked to the App [7]. These educational efforts underline the observed knowledge gap regarding the indication for and correct application of PCCDs. Perhaps more practical training with instruction of additional palpable anatomic landmarks besides the level of the trochanters such as the relation of the upper belt border to the anterior superior iliac spine is needed to avoid grossly incorrect PCCD positioning and could increase the rate of correct PCCD applications.

\section{Conclusions}

Only one third (34\%) of patients with pelvic fractures assigned to the RR had a PCCD placed. Moreover, of these, 39\% were applied incorrectly. These results, in accordance with similar results from the recent literature, clearly demonstrate the need for focused preclinical and clinical education programs on when and how to apply a PCCD.

The observed rate of potential aggravated adverse effects of PCCD's seems to be higher in the treated group irrespective of the fracture pattern. Higher patient numbers are needed to balance the live saving benefits of PCCD's against potential adverse effects of its application.

In the meantime, the PCCD remains the gold standard, however by rising the awareness of correct indication and positioning in the catchment area of this level I trauma center potential adverse effects could likely be minimised and benefits increased.

Author Contributions: Conceptualization and Methodology, V.K., F.J.P.B. and R.B.; Software, Medfolio (Nexus AG, Donaueschingen, Germany) and Picture Archiving and Communication System (Phönix-PACS GmbH, Freiburg i.Br, Germany) and SPSS (IBM ${ }^{\circledR}$ SPSS $^{\circledR}$ Statistics 24); formal analysis and investigation, V.K., S.S., B.-C.L., M.S. and J.F.; data curation, V.K.; Writing-original draft preparation, V.K., N.v.V., R.B. and B.-C.L.; Writing-review and editing, all authors; visualisation, V.K., R.B. and B.-C.L.; Supervision, R.B., F.J.P.B. and B.-C.L. All authors have read and agreed to the published version of the manuscript.

Funding: This research received no external funding.

Institutional Review Board Statement: The study was conducted according to the guidelines of the Declaration of Helsinki, and approved by the Ethics Committee of Northwest- and Central Switzerland (project ID 2018-00411).

Informed Consent Statement: Patient consent was waived. No consent could be obtained for the injury patterns examined prior to data collection. This fact was explicitly communicated to the ethics committee. The ethics committee granted permission to carry out the study and to publish the study.

Data Availability Statement: The data presented in this study are available on request from the corresponding author. The data are not publicly available due to privacy reasons.

Conflicts of Interest: The authors declare no conflict of interest.

\section{References}

1. Freitas, C.D.; Garotti, J.E.R.; Nieto, J.; Guimarães, R.P.; Ono, N.K.; Honda, E.; Polesello, G.C. There Have Been Changes in the Incidence and Epidemiology of Pelvic Ring Fractures in Recent Decades? Rev. Bras. Ortop. 2013, 48, 475-481. [CrossRef]

2. Toimela, J.; Brinck, T.; Handolin, L. Evolution of High-Energy Pelvic Trauma in Southern Finland: A 12-Year Experience from a Tertiary Trauma Centre. Eur. J. Trauma Emerg. Surg. 2019. [CrossRef]

3. Wong, J.M.-L.; Bucknill, A. Fractures of the Pelvic Ring. Injury 2017, 48, 795-802. [CrossRef] [PubMed]

4. Polytrauma Guideline Update Group. Level 3 Guideline on the Treatment of Patients with Severe/Multiple Injuries. Eur. J. Trauma Emerg. Surg. 2018, 44, 3-271. [CrossRef]

5. Hemorrhage in Major Pelvic Fractures. Available online: https:/ / europepmc.org/article/med/3046004 (accessed on 14 June 2020).

6. Ben-Menachem, Y.; Coldwell, D.M.; Young, J.W.; Burgess, A.R. Hemorrhage Associated with Pelvic Fractures: Causes, Diagnosis, and Emergent Management. Am. J. Roentgenol. 1991, 157, 1005-1014. [CrossRef] [PubMed] 
7. ATLS 10th Edition Offers New Insights into Managing Trauma Patients. Available online: https://bulletin.facs.org/2018/06/ atls-10th-edition-offers-new-insights-into-managing-trauma-patients / (accessed on 11 April 2020).

8. Coccolini, F.; Stahel, P.F.; Montori, G.; Biffl, W.; Horer, T.M.; Catena, F.; Kluger, Y.; Moore, E.E.; Peitzman, A.B.; Ivatury, R.; et al. Pelvic Trauma: WSES Classification and Guidelines. World J. Emerg. Surg. 2017, 12, 5. [CrossRef]

9. Bottlang, M.; Krieg, J.C.; Mohr, M.; Simpson, T.S.; Madey, S.M. Emergent Management of Pelvic Ring Fractures with Use of Circumferential Compression. JBJS 2002, 84, S43. [CrossRef] [PubMed]

10. DeAngelis, N.A.; Wixted, J.J.; Drew, J.; Eskander, M.S.; Eskander, J.P.; French, B.G. Use of the Trauma Pelvic Orthotic Device (T-POD) for Provisional Stabilisation of Anterior-Posterior Compression Type Pelvic Fractures: A Cadaveric Study. Injury 2008, 39, 903-906. [CrossRef]

11. Krieg, J.C.; Mohr, M.; Ellis, T.J.; Simpson, T.S.; Madey, S.M.; Bottlang, M. Emergent Stabilization of Pelvic Ring Injuries by Controlled Circumferential Compression: A Clinical Trial. J. Trauma Acute Care Surg. 2005, 59, 659-664. [CrossRef]

12. Croce, M.A.; Magnotti, L.J.; Savage, S.A.; Wood, G.W.; Fabian, T.C. Emergent Pelvic Fixation in Patients with Exsanguinating Pelvic Fractures. J. Am. Coll. Surg. 2007, 204, 935-939; discussion 940-942. [CrossRef]

13. Gardner, M.J.; Parada, S.; Chip Routt, M.L. Internal Rotation and Taping of the Lower Extremities for Closed Pelvic Reduction. J. Orthop. Trauma 2009, 23, 361-364. [CrossRef] [PubMed]

14. Gänsslen, A.; Lindahl, J.; Füchtmeier, B. Emergency Stabilization: Pelvic Binder. In Pelvic Ring Fractures; Gänsslen, A., Lindahl, J., Grechenig, S., Füchtmeier, B., Eds.; Springer International Publishing: Cham, Germany, 2021; pp. 135-140, ISBN 978-3-030-54730-1.

15. Littlejohn, L.; Bennett, B.L.; Drew, B. Application of Current Hemorrhage Control Techniques for Backcountry Care: Part Two, Hemostatic Dressings and Other Adjuncts. Wilderness Environ. Med. 2015, 26, 246-254. [CrossRef]

16. Severe Pelvic Injury with Pelvic Mass Hemorrhage: Determining Severity of Hemorrhage and Clinical Experience with Emergency Stabilization. Available online: https:/ / europepmc.org/article/med/9005561 (accessed on 12 April 2020).

17. Burkhardt, M.; Culemann, U.; Seekamp, A.; Pohlemann, T. Strategies for surgical treatment of multiple trauma including pelvic fracture. Review of the literature. Unfallchirurg 2005, 108, 812, 814-820. [CrossRef]

18. Bonner, T.J.; Eardley, W.G.P.; Newell, N.; Masouros, S.; Matthews, J.J.; Gibb, I.; Clasper, J.C. Accurate Placement of a Pelvic Binder Improves Reduction of Unstable Fractures of the Pelvic Ring. J. Bone Jt. Surg. Br. 2011, 93, 1524-1528. [CrossRef]

19. Bottlang, M.; Simpson, T.; Sigg, J.; Krieg, J.C.; Madey, S.M.; Long, W.B. Noninvasive Reduction of Open-Book Pelvic Fractures by Circumferential Compression. J. Orthop. Trauma 2002, 16, 367-373. [CrossRef] [PubMed]

20. Suzuki, T.; Kurozumi, T.; Watanabe, Y.; Ito, K.; Tsunoyama, T.; Sakamoto, T. Potentially Serious Adverse Effects from Application of a Circumferential Compression Device for Pelvic Fracture: A Report of Three Cases. Trauma Case Rep. 2020, 26. [CrossRef]

21. Schaller, T.M.; Sims, S.; Maxian, T. Skin Breakdown Following Circumferential Pelvic Antishock Sheeting: A Case Report. J. Orthop. Trauma 2005, 19, 661-665. [CrossRef] [PubMed]

22. Krieg, J.C.; Mohr, M.; Mirza, A.J.; Bottlang, M. Pelvic Circumferential Compression in the Presence of Soft-Tissue Injuries: A Case Report. J. Trauma 2005, 59, 470-472. [CrossRef]

23. Mason, L.W.; Boyce, D.E.; Pallister, I. Catastrophic Myonecrosis Following Circumferential Pelvic Binding after Massive Crush Injury: A Case Report. Inj. Extra 2009, 40, 84-86. [CrossRef]

24. Shank, J.R.; Morgan, S.J.; Smith, W.R.; Meyer, F.N. Bilateral Peroneal Nerve Palsy Following Emergent Stabilization of a Pelvic Ring Injury. J. Orthop. Trauma 2003, 17, 67-70. [CrossRef]

25. Garner, A.A.; Hsu, J.; McShane, A.; Sroor, A. Hemodynamic Deterioration in Lateral Compression Pelvic Fracture After Prehospital Pelvic Circumferential Compression Device Application. Air Med. J. 2017, 36, 272-274. [CrossRef] [PubMed]

26. Bakhshayesh, P.; Boutefnouchet, T.; Tötterman, A. Effectiveness of Non Invasive External Pelvic Compression: A Systematic Review of the Literature. Scand. J. Trauma, Resusc. Emerg. Med. 2016, 24, 73. [CrossRef] [PubMed]

27. STROBE Statement: Home. Available online: https://www.strobe-statement.org/index.php?id=strobe-home (accessed on 14 June 2020).

28. Olson, C.J.; Arthur, M.; Mullins, R.J.; Rowland, D.; Hedges, J.R.; Mann, N.C. Influence of Trauma System Implementation on Process of Care Delivered to Seriously Injured Patients in Rural Trauma Centers. Surgery 2001, 130, 273-279. [CrossRef]

29. van Olden, G.D.J.; Dik Meeuwis, J.; Bolhuis, H.W.; Boxma, H.; Goris, R.J.A. Clinical Impact of Advanced Trauma Life Support. Am. J. Emerg. Med. 2004, 22, 522-525. [CrossRef]

30. Siebert, H. White book of severely injured-Care of the DGU. Recommendations on structure, organization and provision of hospital equipment for care of severely injured in the Federal Republic of Germany. Unfallchirurg 2006, 109, 815-820. [CrossRef]

31. Rommens, P.M.; Hofmann, A. Comprehensive Classification of Fragility Fractures of the Pelvic Ring: Recommendations for Surgical Treatment. Injury 2013, 44, 1733-1744. [CrossRef]

32. Osler, T.; Baker, S.P.; Long, W. A Modification of the Injury Severity Score That Both Improves Accuracy and Simplifies Scoring. J. Trauma Acute Care Surg. 1997, 43, 922-926. [CrossRef]

33. Lavoie, A.; Moore, L.; LeSage, N.; Liberman, M.; Sampalis, J.S. The New Injury Severity Score: A More Accurate Predictor of In-Hospital Mortality than the Injury Severity Score. J. Trauma Acute Care Surg. 2004, 56, 1312-1320. [CrossRef]

34. Ringdal, K.G.; Coats, T.J.; Lefering, R.; Di Bartolomeo, S.; Steen, P.A.; Røise, O.; Handolin, L.; Lossius, H.M. Utstein TCD expert panel. The Utstein Template for Uniform Reporting of Data Following Major Trauma: A Joint Revision by SCANTEM, TARN, DGU-TR and RITG. Scand. J. Trauma Resusc. Emerg. Med. 2008, 16, 7. [CrossRef] [PubMed]

35. Tile, M. Pelvic Ring Fractures: Should They Be Fixed? J. Bone Jt. Surg. Br. 1988, 70, 1-12. [CrossRef] [PubMed] 
36. Tile, M. Null Acute Pelvic Fractures: I. Causation and Classification. J. Am. Acad. Orthop. Surg. 1996, 4, 143-151. [CrossRef]

37. Judet, R.; Judet, J.; Letournel, E. Fractures of the acetabulum: Classification and surgical approaches for open reduction. Preliminary report. J. Bone Jt. Surg. Am. 1964, 46, 1615-1646. [CrossRef]

38. Sacral Fractures: An Important Problem. Retrospective Analysis of 236 Cases. Available online: https:/ / europepmc.org/article/ med/3338224 (accessed on 15 April 2020).

39. Tan, E.C.T.H.; van Stigt, S.F.L.; van Vugt, A.B. Effect of a New Pelvic Stabilizer (T-POD®) on Reduction of Pelvic Volume and Haemodynamic Stability in Unstable Pelvic Fractures. Injury 2010, 41, 1239-1243. [CrossRef] [PubMed]

40. Bryson, D.J.; Davidson, R.; Mackenzie, R. Pelvic Circumferential Compression Devices (PCCDs): A Best Evidence Equipment Review. Eur. J. Trauma Emerg. Surg. 2012, 38, 439-442. [CrossRef] [PubMed]

41. Vaidya, R.; Roth, M.; Zarling, B.; Zhang, S.; Walsh, C.; Macsuga, J.; Swartz, J. Application of Circumferential Compression Device (Binder) in Pelvic Injuries: Room for Improvement. West. J. Emerg. Med. 2016, 17, 766-774. [CrossRef]

42. Toth, L.; King, K.L.; McGrath, B.; Balogh, Z.J. Efficacy and Safety of Emergency Non-Invasive Pelvic Ring Stabilisation. Injury 2012, 43, 1330-1334. [CrossRef] [PubMed]

43. Bakhshayesh, P.; Heljesten, S.; Weidenhielm, L.; Enocson, A. Experience and Availability of Pelvic Binders at Swedish Trauma Units; A Nationwide Survey. Bull. Emerg. Trauma 2018, 6, 221-225. [CrossRef]

44. Jain, S.; Bleibleh, S.; Marciniak, J.; Pace, A. A National Survey of United Kingdom Trauma Units on the Use of Pelvic Binders. Int. Orthop. 2013, 37, 1335-1339. [CrossRef] [PubMed]

45. Zingg, T.; Piaget-Rossel, R.; Steppacher, J.; Carron, P.-N.; Dami, F.; Borens, O.; Albrecht, R.; Darioli, V.; Taffé, P.; Maudet, L.; et al. Prehospital Use of Pelvic Circumferential Compression Devices in a Physician-Based Emergency Medical Service: A 6-Year Retrospective Cohort Study. Sci. Rep. 2020, 10, 5106. [CrossRef]

46. Prasarn, M.L.; Small, J.; Conrad, B.; Horodyski, N.; Horodyski, M.; Rechtine, G.R. Does Application Position of the T-POD Affect Stability of Pelvic Fractures? J. Orthop. Trauma 2013, 27, 262-266. [CrossRef]

47. Wincheringer, D.; Langheinrich, A.; Schmidt-Horlohé, K.; Wohlrath, B.; Schröder, A.; Hoffmann, R.; Schweigkofler, U. Analyse der Positionierung von Beckengurten in der Notfallversorgung von Instabilen Beckenfrakturen; German Medical Science GMS Publishing House: Düsseldorf, Germany, 2015; pp. 29-1344.

48. Williamson, F.; Coulthard, L.G.; Hacking, C.; Martin-Dines, P. Identifying Risk Factors for Suboptimal Pelvic Binder Placement in Major Trauma. Injury 2020. [CrossRef] [PubMed]

49. Naseem, H.; Nesbitt, P.; Sprott, D.; Clayson, A. An Assessment of Pelvic Binder Placement at a UK Major Trauma Centre. Annals 2017, 100, 101-105. [CrossRef]

50. Henning, S.; Norris, R.; Hill, C.E. Pelvic Binder Placement in a Regional Trauma Centre. J. Paramed. Pract. 2018, 10 , 463-467. [CrossRef]

51. Knops, S.P.; Schep, N.W.L.; Spoor, C.W.; van Riel, M.P.J.M.; Spanjersberg, W.R.; Kleinrensink, G.J.; van Lieshout, E.M.M.; Patka, P.; Schipper, I.B. Comparison of Three Different Pelvic Circumferential Compression Devices: A Biomechanical Cadaver Study. JBJS 2011, 93, 230-240. [CrossRef]

52. How (Un)Useful Is the Pelvic Ring Stability Examination in Blunt Trauma Patients: Journal of Trauma and Acute Care Surgery. Available online: https://journals.lww.com/jtrauma/Fulltext/2009/03000/How_Un_Useful_is_the_Pelvic_Ring_Stability.34 .aspx (accessed on 21 April 2020).

53. Schweigkofler, U.; Wohlrath, B.; Trentsch, H.; Greipel, J.; Tamimi, N.; Hoffmann, R.; Wincheringer, D. Diagnostics and Early Treatment in Prehospital and Emergency-Room Phase in Suspicious Pelvic Ring Fractures. Eur. J. Trauma Emerg. Surg. 2018, 44, 747-752. [CrossRef] [PubMed]

54. Significance of Physical Examination and Radiography of the Pelvis during Treatment in the Shock Emergency Room. Available online: https: / / europepmc.org/article/med/12955235 (accessed on 21 April 2020).

55. Magner, A.; Smith, N.; Douglin, T. Application of Pelvic Binders by Student Paramedics: An Observational Cohort Study. J. Paramed. Pract. 2019, 11, 526-531. [CrossRef]

56. Importance of the Correct Placement of the Pelvic Binder for Stabilisation of Haemodynamically Compromised Patients. Available online: https: / / europepmc.org/article/med/23296559 (accessed on 19 April 2020).

57. Fu, C.-Y.; Wu, Y.-T.; Liao, C.-H.; Kang, S.-C.; Wang, S.-Y.; Hsu, Y.-P.; Lin, B.-C.; Yuan, K.-C.; Kuo, I.-M.; Ouyang, C.-H. Pelvic Circumferential Compression Devices Benefit Patients with Pelvic Fractures Who Need Transfers. Am. J. Emerg. Med. 2013, 31, 1432-1436. [CrossRef]

58. Ganz, R.; Rj, K.; Rp, J.; Küffer, J. The Antishock Pelvic Clamp. Clin. Orthop. Relat. Res. 1991, 71-78. [CrossRef]

59. Pohlemann, T.; Culemann, U.; Tosounidis, G.; Kristen, A. Application of the pelvic C-clamp. Unfallchirurg 2004, 107, 1185-1191. [CrossRef]

60. Tiemann, A.H.; Böhme, J.; Josten, C. Use of the pelvic clamp in polytraumatised patients with unstable disruption of the posterior pelvic ring. Modified technique-risks-problems. Orthopade 2006, 35, 1225-1236. [CrossRef]

61. Kellam, J.F. The Role of External Fixation in Pelvic Disruptions. Clin. Orthop. Relat. Res. 1989, 241, 66-82. [CrossRef]

62. Broos, P.; Vanderschot, P.; Craninx, L.; Reynders, P.; Rommens, P. Internal hemorrhages associated with fractures of the pelvic girdle. Importance of early stabilization using an external fixator. Acta Orthop. Belg. 1993, 59, 130-138. [PubMed]

63. Gänsslen, A.; Pohlemann, T.; Krettek, C. A simple supraacetabular external fixation for pelvic ring fractures. Oper. Orthop. Traumatol. 2005, 17, 296-312. [CrossRef] [PubMed] 
64. Kim, W.Y.; Hearn, T.C.; Seleem, O.; Mahalingam, E.; Stephen, D.; Tile, M. Effect of Pin Location on Stability of Pelvic External Fixation. Clin. Orthop. Relat. Res. 1999, 237-244. [CrossRef]

65. Rommens, P.M.; Hofmann, A.; Hessmann, M.H. Management of Acute Hemorrhage in Pelvic Trauma: An Overview. Eur. J. Trauma 2010, 36, 91-99. [CrossRef] [PubMed]

66. Schmal, H.; Larsen, M.S.; Stuby, F.; Strohm, P.C.; Reising, K.; Burri, K.G. Effectiveness and Complications of Primary C-Clamp Stabilization or External Fixation for Unstable Pelvic Fractures. Injury 2019, 50, 1959-1965. [CrossRef] [PubMed]

67. Audretsch, C.K.; Mader, D.; Bahrs, C.; Trulson, A.; Höch, A.; Herath, S.C.; Küper, M.A. Comparison of Pelvic C-Clamp and Pelvic Binder for Emergency Stabilization and Bleeding Control in Type-C Pelvic Ring Fractures. Sci. Rep. 2021, 11. [CrossRef]

68. Zeckey, C.; Cavalcanti Kußmaul, A.; Suero, E.M.; Kammerlander, C.; Greiner, A.; Woiczinski, M.; Braun, C.; Flatz, W.; Boecker, W.; Becker, C.A. The T-Pod Is as Stable as Supraacetabular Fixation Using 1 or 2 Schanz Screws in Partially Unstable Pelvic Fractures: A Biomechanical Study. Eur. J. Med. Res. 2020, 25. [CrossRef]

69. Spanjersberg, W.R.; Knops, S.P.; Schep, N.W.L.; van Lieshout, E.M.M.; Patka, P.; Schipper, I.B. Effectiveness and Complications of Pelvic Circumferential Compression Devices in Patients with Unstable Pelvic Fractures: A Systematic Review of Literature. Injury 2009, 40, 1031-1035. [CrossRef]

70. Jowett, A.J.L.; Bowyer, G.W. Pressure Characteristics of Pelvic Binders. Injury 2007, 38, 118-121. [CrossRef]

71. Knops, S.P.; van Riel, M.P.J.M.; Goossens, R.H.M.; van Lieshout, E.M.M.; Patka, P.; Schipper, I.B. Measurements of the Exerted Pressure by Pelvic Circumferential Compression Devices. Open Orthop. J. 2010, 4, 101-106. [CrossRef] [PubMed]

72. Knops, S.P.; Van Lieshout, E.M.M.; Spanjersberg, W.R.; Patka, P.; Schipper, I.B. Randomised Clinical Trial Comparing Pressure Characteristics of Pelvic Circumferential Compression Devices in Healthy Volunteers. Injury 2011, 42, 1020-1026. [CrossRef] [PubMed] 